University of Nebraska - Lincoln

DigitalCommons@University of Nebraska - Lincoln

\title{
Consequences of recent Southern Hemisphere winter variability on polar mesospheric clouds
}

\author{
David E. Siskind \\ Naval Research Laboratory, siskind@nrl.navy.mil \\ Michael H. Stevens \\ Naval Research Laboratory \\ Mark Hervig \\ GATS, Inc., m.e.hervig@gats-inc.com \\ Fabrizio Sassi \\ Naval Research Laboratory, fabrizio.sassi@nrl.navy.mil \\ Karl Hoppel \\ Naval Research Laboratory, karl.hoppel@nrl.navy.mil \\ See next page for additional authors
}

Follow this and additional works at: https://digitalcommons.unl.edu/usnavyresearch

Siskind, David E.; Stevens, Michael H.; Hervig, Mark; Sassi, Fabrizio; Hoppel, Karl; Englert, Christoph R.; and Kochenash, Andrew J., "Consequences of recent Southern Hemisphere winter variability on polar mesospheric clouds" (2011). U.S. Navy Research. 45.

https://digitalcommons.unl.edu/usnavyresearch/45

This Article is brought to you for free and open access by the U.S. Department of Defense at DigitalCommons@University of Nebraska - Lincoln. It has been accepted for inclusion in U.S. Navy Research by an authorized administrator of DigitalCommons@University of Nebraska - Lincoln. 


\section{Authors}

David E. Siskind, Michael H. Stevens, Mark Hervig, Fabrizio Sassi, Karl Hoppel, Christoph R. Englert, and Andrew J. Kochenash 


\title{
Consequences of recent Southern Hemisphere winter variability on polar mesospheric clouds
}

\author{
David E. Siskind ${ }^{\mathrm{a}, *}$, Michael H. Stevens ${ }^{\mathrm{a}}$, Mark Hervig ${ }^{\mathrm{b}}$, Fabrizio Sassi ${ }^{\mathrm{a}}$, Karl Hoppel ${ }^{\mathrm{c}}$, \\ Christoph R. Englert ${ }^{\mathrm{a}}$, Andrew J. Kochenash ${ }^{\mathrm{d}}$ \\ a Space Science Division, Naval Research Laboratory, Washington DC, USA \\ b GATS, Inc., Driggs Idaho, USA \\ c Remote Sensing Division, Naval Research Laboratory, Washington DC, USA \\ d Computational Physics, Inc., Springfield VA, USA
}

\section{A R T I C L E I N F O}

\section{Article history:}

Received 31 January 2011

Received in revised form

4 May 2011

Accepted 27 June 2011

Available online 3 July 2011

Keywords:

Polar mesospheric clouds

Mesopause

Teleconnections

\begin{abstract}
A B S T R A C T
Variations in the Southern Hemisphere (SH) winter of 2007, 2008 and 2009 had important consequences on polar mesospheric clouds (PMCs) observed in the corresponding Northern summers. Specifically, the stratospheric SH winter of 2007 was observed to be warmer than in 2008 and 2009. Using the high altitude analysis from the Navy Operational Global Atmospheric Prediction SystemAdvanced Level Physics High Altitude (NOGAPS-ALPHA) forecast/assimilation system we show that this warmth was linked to similar temperature increases in the high latitude summer mesosphere. These temperature changes led to a dramatic reduction in PMC occurrence (factor of 5-6) recorded by the SHIMMER instrument at sub-arctic latitudes and a factor of 2 decrease in total ice water content in PMCs seen by the SOFIE instrument on the NASA AIM satellite. Microphysical modeling confirms the overall effect of these temperature changes on PMCs at high latitudes; however, a detailed comparison of the cloud occurrence with the SHIMMER data for all three years shows that the clouds are associated with a surprisingly wide range (130-165 K) of temperatures.
\end{abstract}

Published by Elsevier Ltd.

\section{Introduction}

It is now generally understood that the climatology of the middle atmosphere differs greatly between Northern and Southern Hemispheres. Due to greater land sea contrasts and greater topography, the North experiences more wintertime planetary wave activity, which leads to greater wave induced heating in the $\mathrm{NH}$ winter stratosphere, a weaker and more easily perturbed $\mathrm{NH}$ polar vortex, and reduced breaking of gravity waves, which contribute to the warm winter stratopause (Yulaeva et al., 1994; Garcia et al., 1992; Hitchman et al., 1989). In recent years, interest has shifted to what these differences might mean for the summer seasons in each hemisphere. Early work by Alexander and Rosenlof (1996) showed that the summer stratosphere is warmer in the $\mathrm{SH}$ relative to the $\mathrm{NH}$ due to greater gravity wave induced forcing in the southern summer. Siskind et al. (2003) showed that these stratospheric hemispheric asymmetries had mesospheric counterparts whereby there would be weaker gravity wave drag in the Southern upper mesosphere. This was suggested as a possible cause of the reduced occurrence of polar mesospheric

\footnotetext{
* Corresponding author. Tel.: +1 2027670928.

E-mail address: siskind@nrl.navy.mil (D.E. Siskind).
}

clouds (PMCs) in the southern summer since weaker gravity wave drag would imply a warmer summer mesopause (Siskind et al., 2005a).

Most recently there has been great interest in so-called teleconnections between wintertime conditions in one hemisphere and the corresponding summer, which occurs simultaneously in the other. For middle atmospheric conditions, this interest was provoked by the unusual Southern winter of 2002. During this winter, several minor stratospheric warmings were observed (Siskind et al., 2005b), culminating in an unprecedented major warming in September (e.g. Allen et al., 2006 and references therein). At the same time, the MACWAVE rocket campaign (Goldberg et al., 2004) reported unusual conditions in the NH summer mesosphere. These included a warmer mesopause and reduced occurrence of polar mesospheric summer Echoes. Model simulations by Becker et al. (2004) and Becker and Fritts (2006) led to the suggestion that the unusually strong planetary wave activity in the Southern Hemisphere initiated a chain of events, which ultimately led to perturbations to the gravity wave drag, which produces the cold summer mesopause.

Subsequent work by Karlsson et al. (2007, 2009a and 2009b) have shown that these long range teleconnections between the winter in one hemisphere and the summer in the other occur quite often. This effect can be documented for both interannual 
variability as well as within a single season. In general, the greater planetary wave activity in the $\mathrm{NH}$ winter, and its large interannual variability, has a major effect on the year-to-year variability of SH PMCs. However, even though the effect is weaker, a connection between the weaker waves in the $\mathrm{SH}$ winter and $\mathrm{NH}$ PMCs could also be detected. The Karlsson et al. (2007) analysis relied on a meteorological analysis, which extended only up to $1 \mathrm{mb}$, thus excluding the mesosphere.

Here we use an analysis, which extends up to $90 \mathrm{~km}$ to look at interannual variability in NH PMC from 2007-2009. Section 2 presents $3 \mathrm{NH}$ seasons of mesospheric cloud data from two instruments, the Solar Occultation for Ice Experiment (SOFIE) and the Spatial Heterodyne Spectrometer for Mesospheric Radicals (SHIMMER). SOFIE is on board the NASA Aeronomy of Ice in the Mesosphere (AIM) satellite (Russell et al., 2009), launched in April 2007 and as of this writing, still making measurements of the high latitude region where PMCs form. SHIMMER was the primary payload of STPSat-1, launched in March 2007 for a mission, which lasted 30 months (Englert et al., 2010). Both SHIMMER and SOFIE observed mesospheric clouds during the 2007, 2008 and 2009 Northern summer seasons, but, as we will discuss, using quite different observational techniques and from different orbits. Section 3 describes results from the synoptic analysis provided by the NOGAPS-ALPHA forecast/assimilation system. In Section 4, we describe the use of NOGAPS-ALPHA temperature, water vapor and winds to drive the Community Aerosol and Radiation Model for Atmospheres (CARMA) microphysical model. We calculate ice water content and compare that with SOFIE observations. Finally, Section 5 concludes and summarizes the major findings of this work.

\section{Observations of mesospheric clouds: SOFIE and SHIMMER}

\subsection{SOFIE}

SOFIE uses the solar occultation technique to retrieve vertical profiles of PMC extinction at eleven wavelengths ranging from the near UV to the mid IR (Gordley et al., 2009). A salient feature of SOFIE is that its observations are confined to a single latitude band. Since AIM is in a polar sun-synchronous orbit, this latitude varies in a narrow range throughout the season, increasing from $65^{\circ}$ in late June to near $70^{\circ}$ in August (cf. figure 3 of Gordley et al., 2009). Also SOFIE sampling remains at a single local time, near 2300 LST for the Northern summer PMC season.

Hervig et al. (2009a) gave an overview of data from the northern summer of 2007 . They noted that after July 1st, there were periodic episodes of PMC decreases coincident with periodic warmings of the summer mesopause region of up to $6 \mathrm{~K}$. Fig. 1 compares the frequency of occurrence for the first three Northern seasons. The SOFIE data version is 1.022 . Fig. 1 shows that SOFIE is so sensitive that it often sees clouds $100 \%$ of the time. This is particularly true for 2008 and 2009. For 2007, there are periods after July 1 st where the cloud occurrence frequency dips to as low as $80 \%$. Hervig et al. (2009a) comment on these reductions in frequency and column ice mass as being consistent with a warming event which caused PMCs to sublimate. Fig. 1 shows that these mid-season cloud reductions were not pronounced in 2008 or 2009.

As described by Hervig et al. (2009b), SOFIE PMC extinctions at IR wavelengths are directly proportional to ice volume density, which given suitable assumptions for ice density, can yield the ice mass density. The vertical integral of the ice mass density yields the column ice mass, also known as ice water content (IWC). Stevens et al. (2010) and Siskind et al. (2007) have shown that the IWC is a useful quantity for comparisons between microphysical

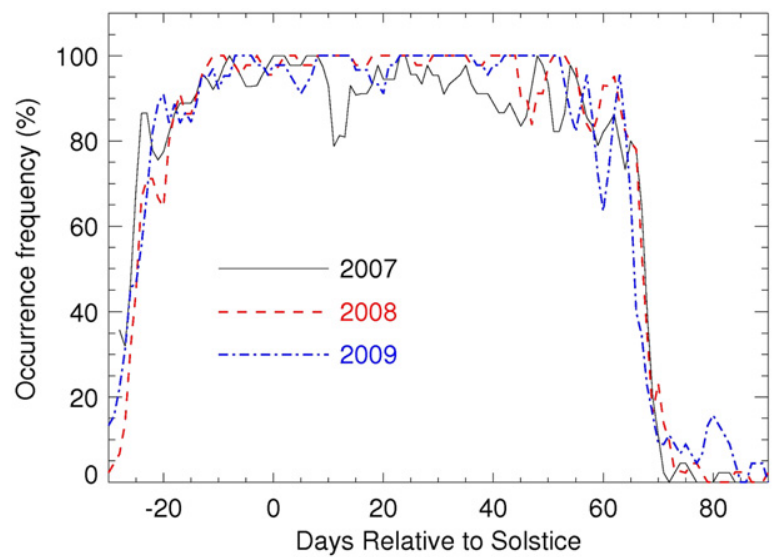

Fig. 1. Frequency of PMC occurrence observed by SOFIE for the NH summers of 2007, 08 and 09. The horizontal axis covers the period from about May 21st to September 21 st. The latitude of the SOFIE occultation roughly tracks the sun and is about $66^{\circ}$ at solstice, rising to near $80^{\circ}$ in September (e.g. http://sofie.gats-inc. com/sofie/index.php).

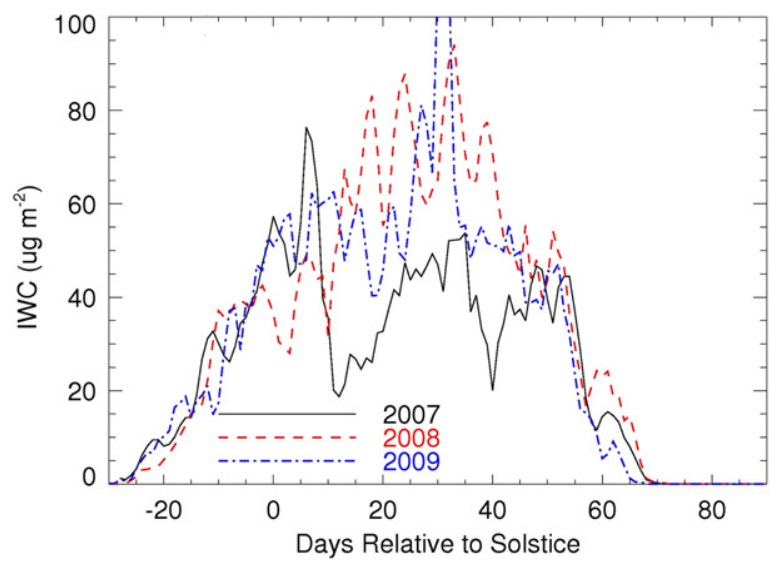

Fig. 2. PMC ice water content measured by SOFIE for the NH summers of 2007 2008 and 2009. The $x$-axis is the same as Fig. 1.

models and satellite measurements. Fig. 2 shows the SOFIE IWC for the 3 years in question. Similar to the occurrence frequencies, starting around July 1 (10 days relative to solstice), the IWC in 2007 stands out as being lower than in 2008 or 2009. This relative reduction persists until early August (around +45 days relative to solstice).

\subsection{SHIMMER}

The SHIMMER data nicely complement the SOFIE data. While, like SOFIE, SHIMMER viewed clouds on the limb, instead of occultation, it viewed the scattered sunlight from the clouds. As discussed in Stevens et al. (2009), solar scattered light from PMCs occasionally enhances the Rayleigh scattered signal observed by SHIMMER near $309 \mathrm{~nm}$ and between about 80 and $85 \mathrm{~km}$ altitude. To identify PMCs we fit an exponential function to the background away from altitudes where PMCs could contaminate the fit. The imposed threshold for cloud detections is furthermore a function of the solar scattering angle to minimize the effects of lighting variations on our detections. As a result of the STPSat-1 orbit, SHIMMER records data over a wide range of local times, with a precession rate of about $1 / 2 \mathrm{~h} /$ day. Over the course of the PMC season, SHIMMER sampled all local times for which the clouds were illuminated. 
Because of the low inclination of the STPSat- 1 orbit $\left(37^{\circ}\right)$, SHIMMER only observed up to $58^{\circ} \mathrm{N}$. The data we showed comes from latitudes between 50 and $58^{\circ} \mathrm{N}$, roughly corresponding to the latitude region where ground based observers see these clouds as noctilucent clouds (NLCs). We also only considered clouds, which occurred at altitudes above $80 \mathrm{~km}$. This largely eliminates the potential problem of clouds occurring in the foreground or background of the SHIMMER line of sight, which would be then erroneously ascribed to temperatures that might be too high (i.e. at too low altitude). This consideration is important for the comparison of SHIMMER cloud occurrences with NOGAPS-ALPHA temperatures in Section 3.

Fig. 3 shows the number of PMCs observed daily by SHIMMER for the three Northern seasons (2007, 2008 and 2009) that it collected data (this is Version 2 of the SHIMMER data). Since the daily sampling rate was nearly identical for each of the three seasons, these histograms are nearly proportional to occurrence frequency. Also shown is the local time of the observation, which for a given date, is slightly different for the three years. Since diurnal variations in PMC frequency are known to be significant, care should be taken to compare the three seasons at as close a local time and date as possible. With this small caveat in mind, it is readily apparent that after solstice, the number of clouds observed in 2007 is much less than in 2008 or 2009. For example, for 11-12 LST (near July 13th-15th in 2007), less than 10 clouds were seen whereas in 2008 (near July 8th-10th) over 40 were seen and about 10-20 detections in 2009 (near July 2nd-4th).

By dividing the cloud detections by the total number of SHIMMER observations along the orbital track, we calculate a frequency of occurrence. Table 1 presents these values along with monthly averaged occurrence frequencies and IWC for SOFIE for the three years. The table shows that in July 2008 and 2009, SOFIE detected a cloud on 98 or $99 \%$ of its orbits. In July 2007, the averaged occurrence frequency, while still high, was less at $92 \%$. The SHIMMER frequency is less than $1 \%$ in 2007, and increases by about a factor of 5 to 6 in 2008 and 2009. The much smaller occurrence frequency and the relatively greater change in frequency seen by SHIMMER relative to SOFIE is probably partially due to the reduced sensitivity of SHIMMER to dim clouds compared with SOFIE. But it is undoubtedly also due to the fact that SHIMMER views clouds at the equatorward edge of their occurrence where they are particularly sensitive to small changes in the background saturation conditions. The monthly averaged SOFIE ice water content shows that the July 2007 reduction in PMC occurrence corresponded to a factor of 2 reductions in ice water content. Other data taken using ground-based lidar at $69^{\circ} \mathrm{N}$ (e.g. Fiedler et al., 2011) show an analogous dip in both frequency and brightness in 2007 relative to adjacent years, at least for the brightest clouds (which tend to track the total IWC)

\section{Meteorological overview}

To quantitatively understand the interannual variability of the summer mesopause we use the NOGAPS-ALPHA forecast/assimilation system, specifically the synoptic analysis first discussed by Hoppel et al. (2008) and Eckermann et al. (2009). The NOGAPSALPHA analysis uses the NRL Atmospheric Variational Data Assimilation System (NAVDAS). NAVDAS is a 3D-variational (3DVAR) system with a $6 \mathrm{~h}$ update cycle that assimilates both conventional operational meteorological data as well as data from the NASA AURA Microwave Limb Sounder (temperature, ozone and $\mathrm{H}_{2} \mathrm{O}$ ) and TIMED Sounding of the Atmosphere with Broadband Emission Radiometry (SABER) temperature data. Hoppel et al. (2008) presented the first realistic mesospheric analysis and showed results for January and February 2006. They assimilated
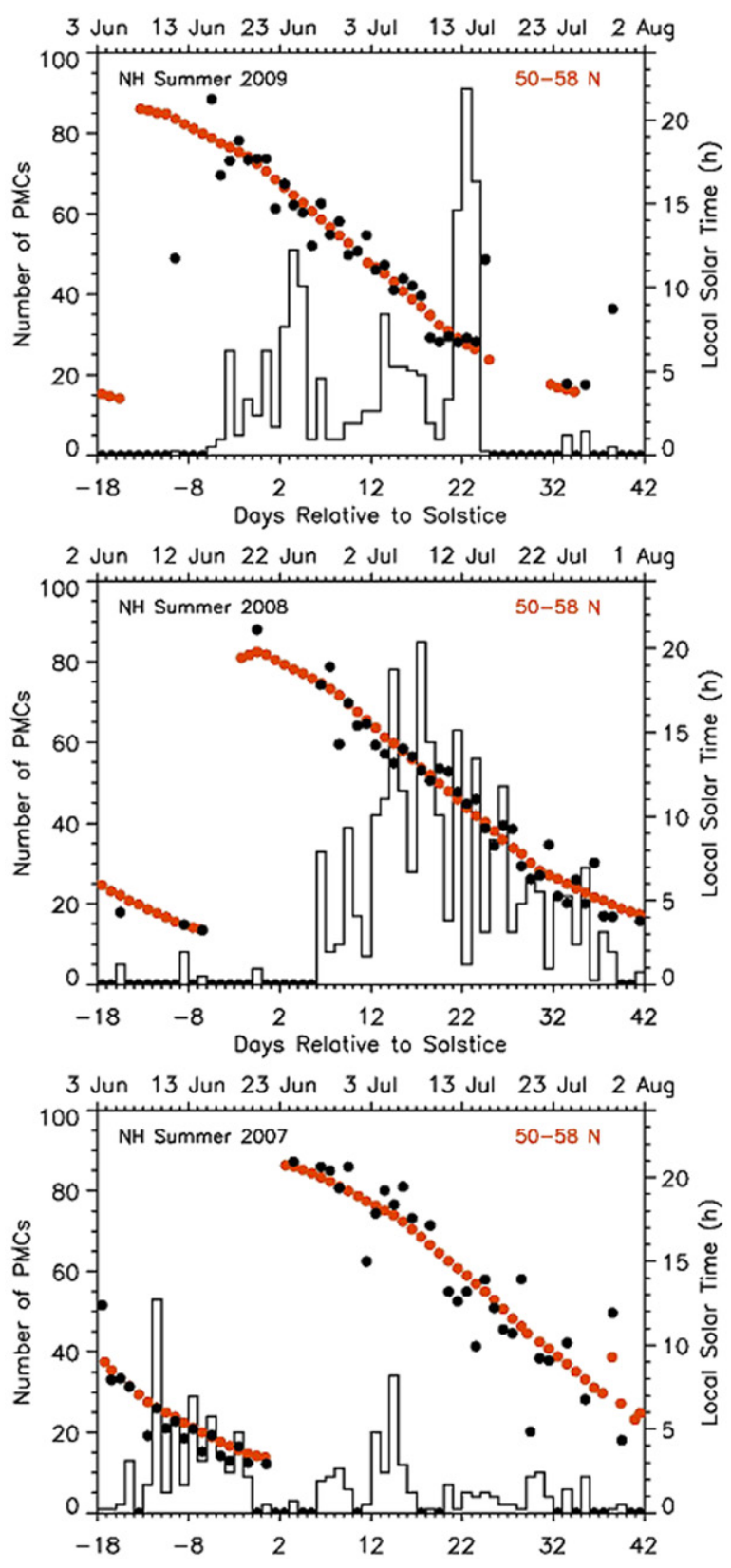

Fig. 3. Frequency of PMC occurrence observed by SHIMMER for the NH summers of 2007, 2008 and 2009. The solid line is the number of PMC observations on a given day, referenced to the left axis. The black circles are the associated daily averaged local times of the cloud detections and the orange dots are the daily averaged local times of all the SHIMMER images, regardless of whether there were clouds or not (both local times are referenced to the right axis). The dates for each year are given by the upper $x$-axis. Note that 2008 was a leap year so the dates differ by 1 day relative to 2007 and 2009. (For interpretation of the references to color in this figure legend, the reader is referred to the web version of this article.)

Table 1

PMC occurrence frequencies (\%) and ice water content $\left(\mu \mathrm{g} \mathrm{m}^{-2}\right)$.

\begin{tabular}{lllll}
\hline Instrument & Month & 2007 & 2008 & 2009 \\
\hline SOFIE $\left(\%, \mu \mathrm{g} \mathrm{m}^{-2}\right.$ ) & June & 95,38 & 95,31 & 95,37 \\
SOFIE & July & 92,36 & 99,69 & 98,61 \\
SOFIE & August & 74,23 & 82,30 & 75,22 \\
SHIMMER (\% only) & July & 0.6 & 3.2 & 3.6 \\
\hline
\end{tabular}


MLS data up to $p=0.01 \mathrm{hPa}$ (about $80 \mathrm{~km}$ in geometric coordinates). Eckermann et al. (2009) extended this capability by assimilating new versions of the MLS (Version 2.2) and SABER (Version 1.07) data up to $0.002 \mathrm{hPa}$ (about $88 \mathrm{~km}$ ) and produced an analysis for the summer of 2007 to support the NASA AIM mission. The forecast model, which is run concurrently with NAVDAS extends up to $p=0.0005 \mathrm{hPa}$ (about $92 \mathrm{~km}$ ); we will show results up to $90 \mathrm{~km}$. Eckermann et al. (2009) also presented some validation of the planetary waves and tides that are captured by the analysis as well as the discussion of the tuning of the gravity wave drag parameterization. The Eckermann et al. (2009) configuration was subsequently frozen as a production configuration, and used to generate $6 \mathrm{~h}$ analyses beyond July 2007 , out to (currently) early 2010. It therefore covers the three NH PMC seasons under consideration, including the entire duration of the SHIMMER mission. Stevens et al. (2010) used an average of the June 2007 analysis fields to initialize the CARMA microphysical model and to calculate the diurnal variation of PMC ice water content.

Fig. 4 summarizes the zonal mean temperature variability in these three seasons by comparing 2008 and 2009 with 2007 for the months of June, July and August. It shows that the temperature differences in June were small, except that June 2007 was slightly colder, than June 2008 and 2009. This is consistent with the variation presented in figure 9 of Stevens et al. (2010). It is also qualitatively consistent with the fact that the cloud frequency in the SOFIE data differed little amongst the three June months. However, for July and August, the comparison of 2007 with 2008 and 2009 reveals interesting global anomaly patterns. The Southern hemisphere shows a vertically alternating pattern of warm and cold anomalies. This pattern is similar to that recently presented by Azeem et al. (2011, submitted to Journal of Geophysical Research). They present ground based temperatures over Antarctica that suggest anomalous conditions in 2007, probably due to enhanced levels of planetary wave activity in 2007 relative to 2008 . The tri-level pattern of alternating warm and cold anomalies also resembles that seen during the $\mathrm{SH}$ minor stratospheric warming observed in August 2002 and reported by Coy et al. (2005) and Siskind et al. (2005b), although the magnitude of the stratospheric temperature increase here $(+15 \mathrm{~K})$ is much less than the $50 \mathrm{~K}$ reported for the 2002 event. The anomaly pattern is also offset from the southern pole. This feature was also previously commented on by Karlsson et al. (2007) as consistent with the weaker wave activity in the $\mathrm{SH}$ relative to the $\mathrm{NH}$ causing the variations to occur on the vortex edge rather than at the highest latitudes, as it does in the $\mathrm{NH}$.

Most significantly for the discussion here, Fig. 4 shows that the 2007 stratospheric warm anomaly appears to extend upward and northward to the summer upper mesosphere. This is also very similar to the patterns identified by Karlsson et al. (2009a) in the Canadian Middle Atmosphere Model; thus warm winter stratospheric anomalies correlate with warm summer mesopause anomalies. The summertime morphology is similar to Karlsson et al. (2009a) in that the warm anomaly tilts upward and

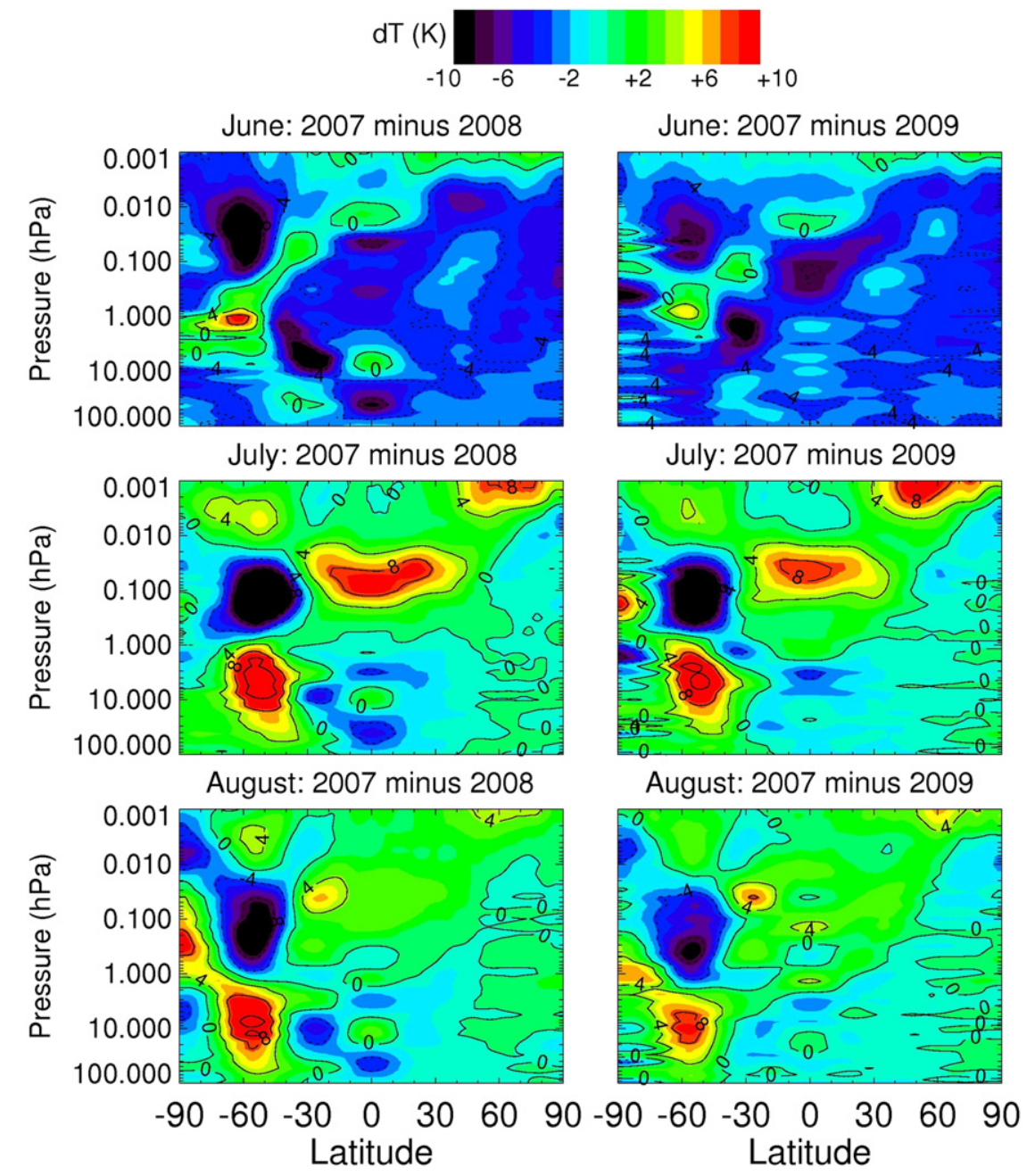

Fig. 4. Comparison of monthly mean zonal average NOGAPS-ALPHA temperature deviations for 3 Northern summer months, in all cases referenced to 2007. 
poleward into the arctic mesopause region. Thus at sub-arctic latitudes, the entire upper mesosphere is warm; however, as one moves to the pole, the warm anomaly rises in altitude, closer to the mesopause. Finally, the July 2007 anomalies are larger than the August 2007 ones. This is also qualitatively consistent with the interannual PMC variation recorded by SOFIE.

Since PMC observations are typically referenced to actual geometric altitudes, it is useful to convert the NOGAPS temperatures to an altitude grid (cf. Stevens et al., 2010). Furthermore, because NOGAPS provides a complete synoptic analysis, it is straightforward to sample the analysis at the times and locations of the SOFIE and SHIMMER measurements. Fig. 5 shows this for the latitudes and local times of the SOFIE observations along with the actual SOFIE temperatures for July and August of the three years in question. This comparison serves as a valuable comparison of the NOGAPS temperatures with an independent dataset.
While one's eye is drawn to the difference for altitudes above $85 \mathrm{~km}$ between NOGAPS and SOFIE, given uncertainties in the $\mathrm{CO}_{2}$ and $\mathrm{O}$ densities required by the SOFIE non-LTE retrieval, this difference may not be surprising. In addition, there may be a cold bias to the NOGAPS temperatures because, as discussed by Schwartz et al. (2008), MLS appears to be up to $10 \mathrm{~K}$ too cold at the highest altitudes in polar summer. As noted by Eckermann et al. (2009), we apply a globally averaged bias-correction to the MLS data; this correction equals $4.3 \mathrm{~K}$ at $0.002 \mathrm{hPa}$ (the top data level). This leaves a remaining cold bias, which in principle, could equal 5-6 K; still much smaller than the almost $20 \mathrm{~K}$ difference between SOFIE and NOGAPS in Fig. 5. However, for purposes of validating the structure of the temperature changes, we argue that it is more useful to highlight the important similarities between the two datasets. This is emphasized in Fig. 6, which compares the year-toyear relative changes in NOGAPS-ALPHA and SOFIE.
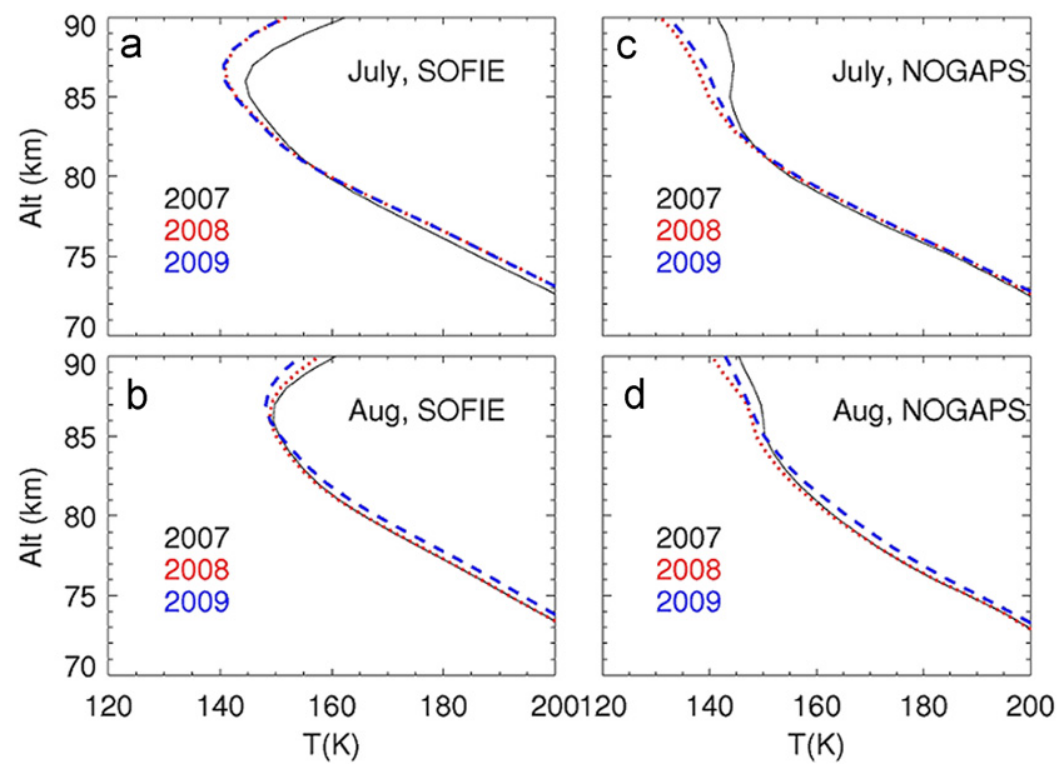

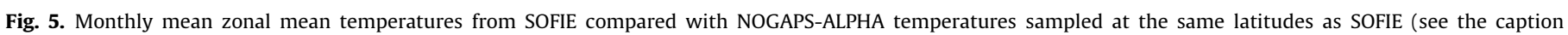
of Fig. 1).
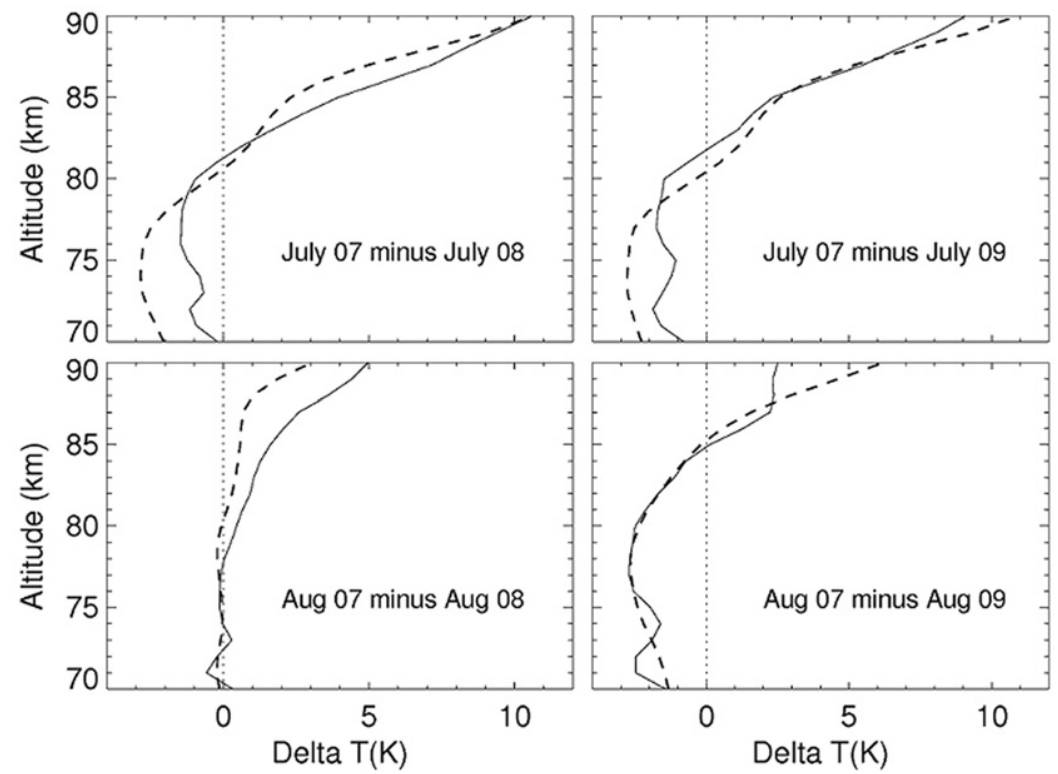

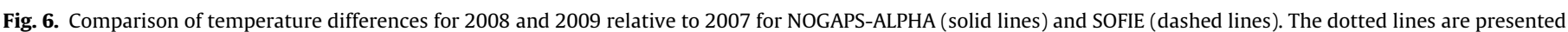
just for reference to zero temperature change. 
Fig. 6 shows that, at all altitudes, even where they disagree, both NOGAPS and SOFIE show the same year-to-year variability and both show that above $80-82 \mathrm{~km}, 2007$ was warmer than 2008 and 2009. Further, both NOGAPS and SOFIE also agree that the warm anomaly was greater in July 2007 relative to 2008 and 2009 than it was in August 2008 and 2009. At $90 \mathrm{~km}$, July the temperature enhancement in 2007 is in the range of 9 to $11 \mathrm{~K}$ in both SOFIE and NOGAPS; in August, both datasets indicate a 3-6 K temperature enhancement. This is strong validation of the NOGAPS-ALPHA temperature variability near its top boundary and also strongly validates both the global pattern of the teleconnection and its detailed vertical structure in the high latitude summer mesopause region suggested in Fig. 4.

Also of interest in Fig. 6 is that the interannual temperature change is quite small at cloud altitudes $(82-83 \mathrm{~km})$, typically between 0 and $1.5 \mathrm{~K}$. However, it grows rapidly with altitude and at $85 \mathrm{~km}$ it is in the range $2-5 \mathrm{~K}$. As we will see, it appears that it is the temperature difference at $85 \mathrm{~km}$, which is important for the greater ice abundance in 2008 and 2009.

At the latitudes sampled by SHIMMER, no SOFIE data is available so we just show mean temperatures from NOGAPS for July of the three years in question (SHIMMER did not detect PMCs in August). Fig. 7 shows that the overall temperatures, which correspond to the SHIMMER observations are much warmer, and the 2007 warm anomaly is greater, than at SOFIE latitudes. At $90 \mathrm{~km}, 2007$ temperatures exceed 2008 and 2009 by 15-20 K. The mean temperatures of $150-160 \mathrm{~K}$ are too high to form PMCs. This is consistent with the much lower frequency of occurrence at SHIMMER latitudes relative to the SOFIE latitudes. While SOFIE sees PMC almost all the time, PMCs are a relatively rare event in the SHIMMER database, generally associated with excursions below the mean temperature.

Fig. 8 illustrates the effect of selecting only those temperatures in NOGAPS-ALPHA associated with SHIMMER cloud observations. It presents two histograms of SHIMMER temperatures for the three years. This is similar to Fig. 1 shown by Shettle et al. (2010), however, they were focused on inter-hemispheric differences and we emphasize interannual variability. In addition, in contrast to the Shettle et al. study, we have removed any tidal variability from the model-data interpretation by sampling NOGAPS-ALPHA at the locations and local times of the observations.

The top panel shows the NOGAPS analyzed temperatures for all the SHIMMER observations in July for the $50-58^{\circ} \mathrm{N}$ latitude band. The bottom panel shows a histogram of temperatures for those SHIMMER observations, which recorded a PMC. Several points are immediately evident. First, the number of occurrences in the bottom panel is much less than in the top. The ratio of the area under the bottom curves relative to the top curves defines

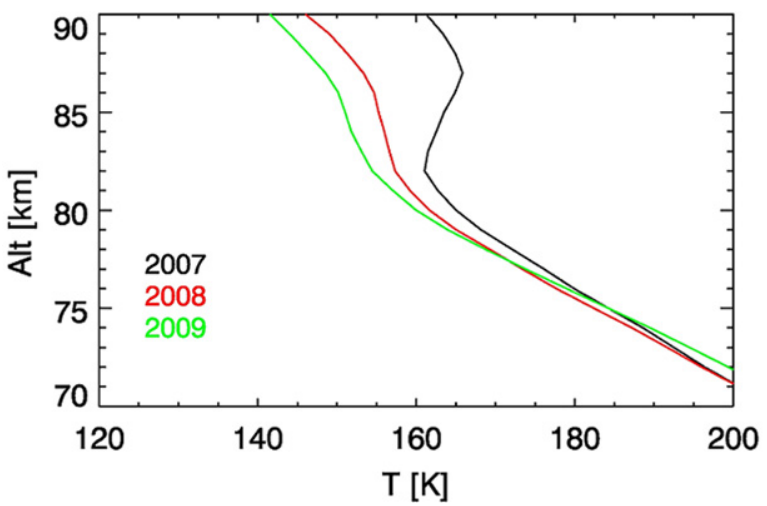

Fig. 7. Mean temperatures from NOGAPS-ALPHA for the month of July corresponding to the times and locations of the SHIMMER observations in the $50-58^{\circ} \mathrm{N}$ latitude band.
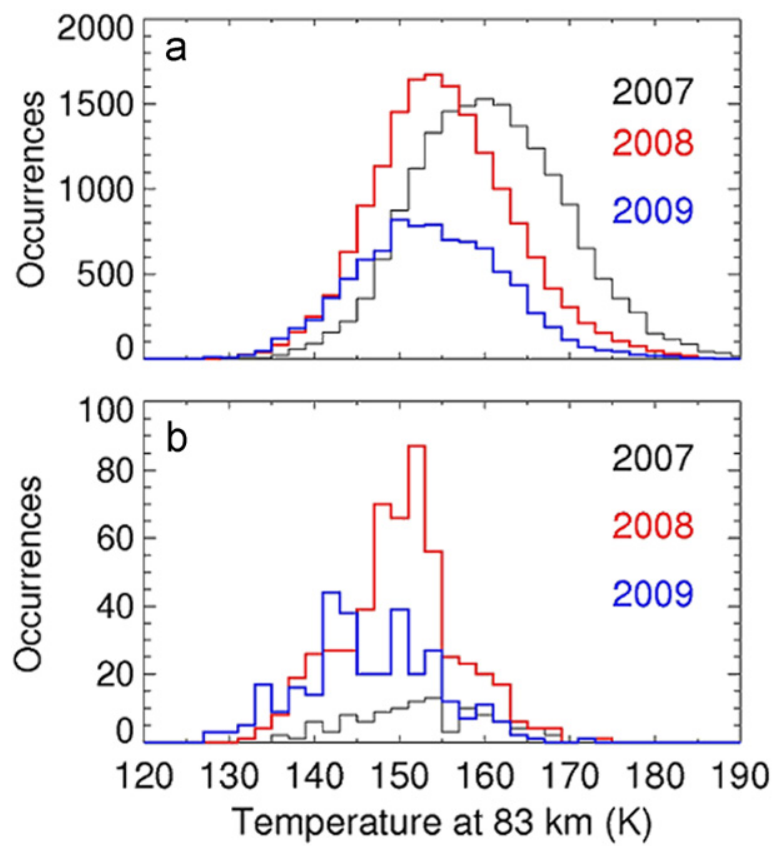

Fig. 8. (a) Histogram of NOGAPS-ALPHA analyzed temperatures at all the locations sampled by SHIMMER for the 3 years indicated. (b) Histogram of NOGAPS-ALPHA analyzed temperatures for those SHIMMER observations, which recorded a PMC.

the frequency of occurrence for SHIMMER that is presented in Table 1 . Second, in the top panel, the distribution of temperatures for 2007 is clearly shifted to greater values than for 2008 and 2009. The mean temperature for the 2007 distribution is about $160 \mathrm{~K}$; the mean for 2008 and 2009 is 155 and $154 \mathrm{~K}$, respectively. These higher temperatures are reflected in the low PMC occurrences for 2007 in Fig. 8b. Third, the temperature distributions in the bottom panel, those associated with the cloud detections, are clearly to the left (i.e. colder) than the overall distributions in the top. This is not surprising. What is somewhat surprising, although not unprecedented, are two features of the bottom panel. First, the temperatures for cloud detections for the three years differ. In other words, there is not one representative temperature for a PMC from one year to the next. The second surprising aspect of Fig. 8b is that there are considerable cloud detections for temperatures normally thought to be too high for PMCs (i.e. greater than $150-155 \mathrm{~K}$ ). This relationship is also particularly surprising since the NOGAPS-ALPHA analyzed temperatures and saturation were previously shown to be a good qualitative indicator of the occurrence of bright clouds seen by SOFIE in the troughs of the 5-day wave in late summer at higher latitudes (Nielsen et al., 2010).

This wide range of temperatures associated with PMC occurrence was also seen by Shettle et al. (2010). They suggested that variations in gravity wave activity or availability of nucleation sites may play a role in the interpretation of PMC occurrences between hemispheres, which may also apply to our interannual study. In addition, there are several other points worth noting. First, PMC detections for limb-viewing temperatures greater than the presumed frost point of $\sim 147 \mathrm{~K}$ are not limited to MLS temperatures. Stevens et al. (2001) reported similar observations using CRISTA data. Since CRISTA temperatures are likely more accurate in the mesopause region than MLS, the problem may not simply be due to MLS bias. Second, it is clear that compared with Shettle et al., there are many more SHIMMER PMC observations at high temperatures, i.e. $160 \mathrm{~K}$. But this should not be surprising since as a limb viewer, SHIMMER is more sensitive to the dim 
clouds than SBUV. Thus it appears that the few clouds, which Shettle et al. (2010) reported for T $>150 \mathrm{~K}$ were only a fraction of what were ultimately present.

\section{Microphysical modeling}

Here we quantitatively evaluate the implications of the 2007 temperature enhancement and its implication for clouds. Our approach is similar to that presented by Stevens et al. (2010). This requires producing a mean temperature field, which preserves the local time information so that a comparison can be made at the proper time of day. We thus averaged together the 1246 hourly synoptic samples of temperature, $\mathrm{H}_{2} \mathrm{O}$, horizontal and vertical winds for both July 2007 and 2008 and placed them on a local time grid. As discussed by Stevens et al. (2010) this removes all longitudinal variability but isolates the effects of the migrating tides. One difference from Stevens et al. (2010) is that we are only interested in modeling PMC at the single local time of the SOFIE measurement $(\sim 23 \mathrm{~h})$. We therefore only use one parcel calculation, rather than the 24 used previously to generate a complete diurnal variation at hourly intervals. As discussed by Stevens et al. (2010) and as apparent in Figs. 7 and 8, the mean temperatures at SHIMMER latitudes are too high to properly represent the conditions under which, the PMCs occur at those latitudes. However, since PMCs are a near-constant occurrence at SOFIE latitudes, the mean temperatures should be much more appropriate and we limit our analysis here to the SOFIE conditions.

As discussed in Stevens et al. (2010), while our intent is to model PMCs coincident with SOFIE, it is unrealistic to simply initialize CARMA from a "cold start" state that is highly supersaturated. It is more likely that the clouds grow along a specific trajectory according to the prevailing wind field. We therefore follow an air parcel for two days using the horizontal winds from NOGAPS-ALPHA and apply a constant progressively decreasing temperature offset, taken from Stevens et al. (2010), until we reach the SOFIE location with appropriate temperature and moisture conditions. Consistent with the approach of Stevens et al., we use one water vapor profile at $69 \mathrm{~N}$ and allow the water to vertically redistribute through sedimentation and sublimation. The temperatures and vertical winds vary along the path as discussed above until the parcel reaches the average SOFIE latitude in July of $68 \mathrm{~N}$. Other inputs such as the rate at which the model cools to ambient conditions, the eddy diffusion, the meteoric smoke distribution and the expression for the equilibrium vapor pressure over ice are the same as used by Stevens et al. (2010).

Fig. 9 shows sample output from the trajectory calculation for both 2007 and 2008. Fig. 9a and c shows the temperature along the parcel path at the indicated latitude and time for 2007 and 2008 , respectively. Variability of these temperatures, for example, the warming at 1.8 days in Fig. 9c is most likely a local time tidal effect as discussed by Stevens et al. (2010). Also superimposed on the temperature contours in Fig. 9a and $\mathrm{c}$ is a solid black line, which represents the altitude of the calculated cloud. Focusing on the 2008 case, we see that the cloud appears to form at $85-86 \mathrm{~km}$ before finally settling to $83 \mathrm{~km}$ at the end of the trajectory. Berger and von Zahn (2007) have addressed the question of at what altitude nucleation begins. They suggested that cloud formation begins no more than $3 \mathrm{~km}$ higher than the final observation at $69^{\circ} \mathrm{N}$. Our results are generally consistent with this and further suggest that it is the temperature increase at $85-86 \mathrm{~km}$, not at the cloud altitude, which is responsible for the interannual cloud difference.

The growth of the cloud for 2008 is indicated in Fig. 9d with a final column ice mass of $64 \mu \mathrm{g} \mathrm{m}^{-2}$. This compares well with the SOFIE observation of $69 \mu \mathrm{g} \mathrm{m}^{-2}$ for July 2008. However, the 2007 calculation yields insignificant clouds (cf. Fig. 9b). This is consistent with our suggestion earlier that the 2007 temperatures were marginal for cloud growth at SOFIE latitudes, although clearly

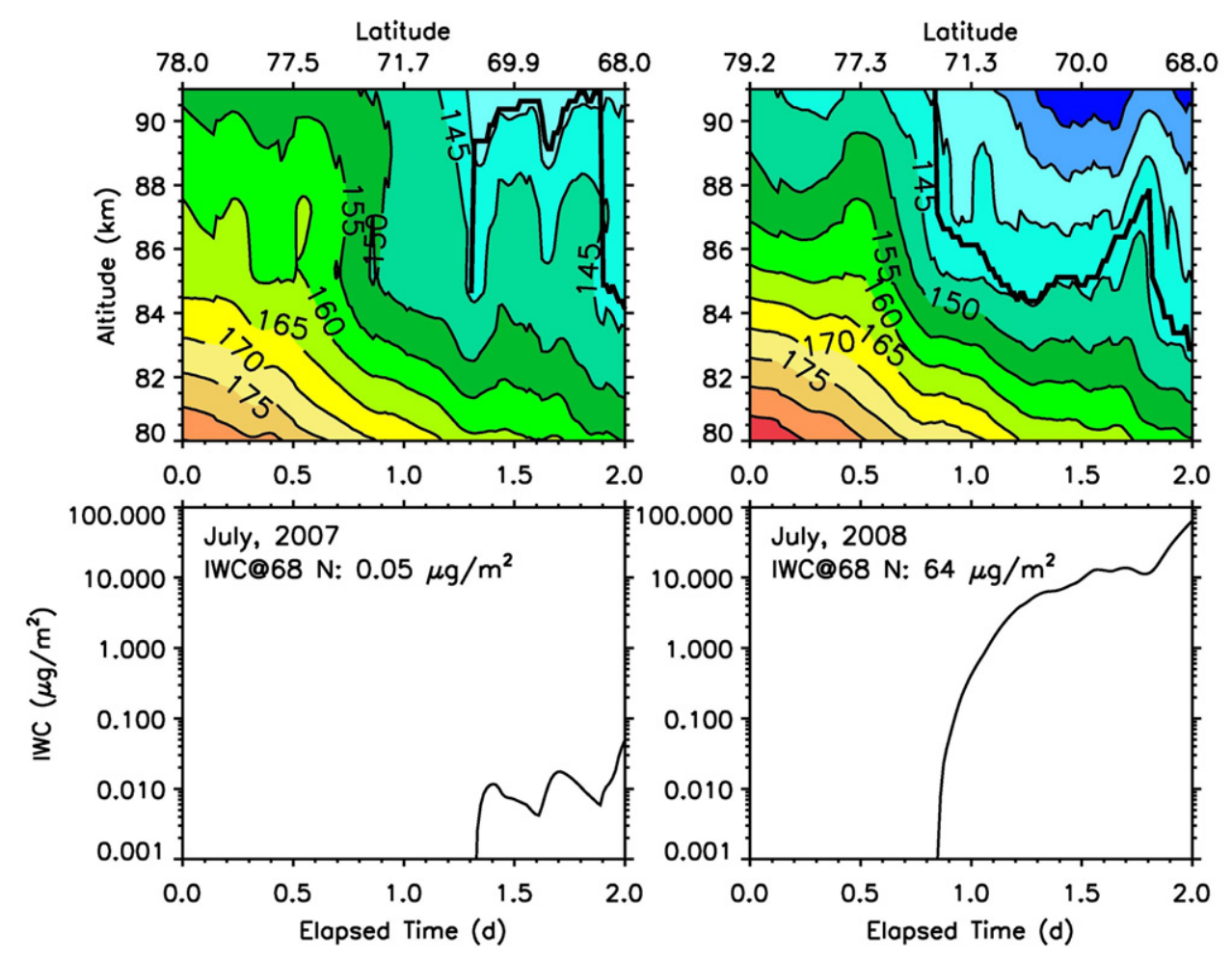

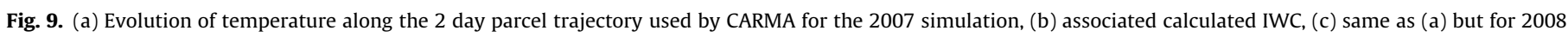

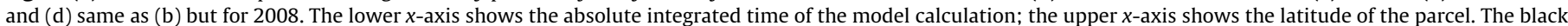
line in (a) and (c) marks the altitude of the calculated ice layer. 
SOFIE did report a much larger IWC in 2007 than our baseline calculation indicates. To explore this further, we performed sensitivity studies where we arbitrary assigned various constant temperature biases to the NOGAPS-ALPHA temperature field that is used in CARMA. The biases tested are $3 \mathrm{~K}$ or less and within the reported systematic uncertainties of the MLS and SABER temperature retrievals (Remsberg et al., 2008; Schwartz et al., 2008) that are assimilated by NOGAPS-ALPHA. The results are shown in Fig. 10.

Fig. 10 shows the results of 10 calculations of IWC, 5 for each year. Each model run assumes the same trajectory and cloud lifetime (i.e. the time over which the cloud is assume to grow). However, to illustrate the sensitivity of our results to possible uncertainties, we varied the temperature in each case by a constant offset ranging from -3 to $+1 \mathrm{~K}$. Also shown in the figure are the IWC observed by SOFIE for 2007 and 2008 as the horizontal lines. As with Fig. 9, it is apparent that in 2007, the conditions for ice growth were marginal at best. Using the NOGAPS-ALPHA temperatures with zero assumed temperature bias yields no clouds. However, the model yields increase dramatically as a temperature offset is introduced from -1 to $-3 \mathrm{~K}$. This may reflect the fact that our monthly mean atmospheric fields are averaging in periods when the atmosphere was too warm, thus skewing our results. The 2008 simulation is less sensitive to the assumed temperature bias. Using NOGAPS-ALPHA with no bias yields a calculated IWC that is within $\sim 20 \%$ of the SOFIE observations in 2008. Assuming progressively colder temperatures increases the calculated ice by a factor of 4 . The figure clearly shows that regardless of the assumed temperature bias, the model predicts greater IWC in 2008 than in 2007, which is in agreement with the observations.

In addition to the arguments presented by Shettle et al. (2010) concerning possible temperature biases, we can suggest two other reasons why a negative model temperature offset might be appropriate. First, in 2007, not all the SOFIE observations recorded PMC. Only 92\% recorded measurable IWC. The mean temperature for that $92 \%$ of the SOFIE data is colder, by about $0.5 \mathrm{~K}$, than a straight average over all the data and our NOGAPSALPHA average does not account for that. In 2008, this is not applicable since SOFIE essentially recorded a cloud in almost $100 \%$ of the occultations. Second, and probably more significant, is that the southward yaw of SABER occurs in mid-July. We have found that the sudden denial of SABER to the NOGAPS-ALPHA assimilation seems to result in a small $(1-4 \mathrm{~K})$ jump in the analyzed

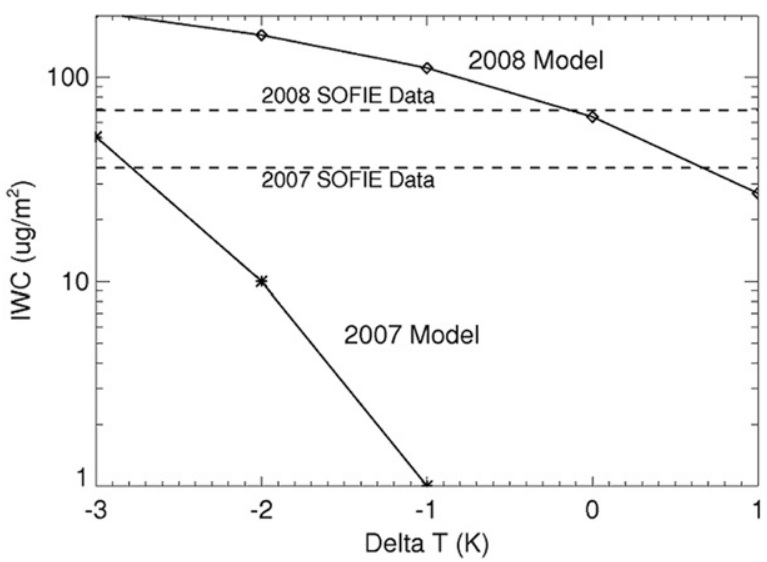

Fig. 10. Calculated IWC for several CARMA model simulations. Each simulation presents the end result of a 2 day calculation as shown in Fig. 8. The differences between the simulations represent various constant temperature offsets applied to the input temperatures. Results for 2007 and 2008 conditions are presented. Also shown for comparison are the observed IWC measured by SOFIE (as the horizontal lines). temperature poleward of $50^{\circ} \mathrm{N}$ and above $80 \mathrm{~km}$ (not shown). By averaging over the entire month, we may be averaging over temperature fields, which are slightly offset. Whether this is an artifact of the how the SABER and MLS instrument temperature biases are handled in the assimilation is unclear; however, it serves as a useful reminder that the analysis depends both upon data, which have uncertainties and upon assumptions about how to assimilate the data, which can also introduce small biases that can convey more significantly to the simulated microphysics.

\section{Summary and conclusions}

The present work has provided insights related to interannual variability in PMCs through teleconnections. First, we have explained the dominant variation in NH PMC over the years 2007-2009. The most dramatic variation was the decrease in July 2007 relative to 2008 and 2009. This decrease was manifested in several consistent ways. Thus we saw an $8 \%$ decrease in the frequency of occurrence in clouds seen in solar occultation by SOFIE near $68^{\circ} \mathrm{N}$, a factor of two decrease in the ice water content observed by SOFIE and a factor of 5-6 in the number of clouds seen by SHIMMER at sub-arctic latitudes. The 2007 PMC reductions are seen to be linked to $\mathrm{SH}$ winter weather as first postulated by Becker et al. (2004) and discussed by Karlsson et al. (2007, 2009b). This is consistent with earlier reports of such inter-hemispheric teleconnections; our results are the first to use a global analysis of the stratosphere and mesosphere with a cloud formation model to document these effects.

It should be noted that it remains somewhat unclear exactly how this inter-hemispheric teleconnection operates. An early investigation of the response of the middle atmosphere to a stratospheric warming perturbation found the effects to be generally limited to the winter hemisphere (Garcia, 1987). One limitation of this work may have been the use of linear Rayleigh damping to describe small-scale frictional dissipation. More recent work with models that utilize a more complete parameterization of small-scale gravity waves (Karlsson et al., 2009a; Kornich and Becker, 2010) have found that the anomalous circulations generated by wintertime wave-mean flow interactions can generate temperature anomalies in the tropics, which by changing the thermal wind balance, can be mediated to anomalies at high summer latitudes. Recent observations of a link between the QBO and inter-hemispheric coupling (Espy et al., 2011) are also consistent with these ideas. The present work certainly supports the robustness of the winter-summer linkage, but a global theoretical explanation for this linkage is beyond the scope of the paper.

As a corollary to understanding the PMC variability, we have compared the analyzed temperatures from NOGAPS-ALPHA with SOFIE. While there are $10 \mathrm{~K}$ differences in the temperature profiles between $86-90 \mathrm{~km}$, for the 3 years in question, the interannual changes displayed by NOGAPS-ALPHA and SOFIE agree very well. Both NOGAPS and SOFIE show that at the SOFIE latitudes, the effect of the temperature anomaly in 2007 was much larger at altitudes above the layer where the ice content peaks (i.e. $83 \mathrm{~km}$ ). This agreement is satisfying confirmation that the NOGAPS-ALPHA analysis diagnoses highly vertically structured changes in upper mesospheric temperature and links them to larger changes elsewhere in the atmosphere.

The question of the non-uniqueness of the temperature-cloud relation, documented by Stevens et al. (2001) and Shettle et al. (2010) and confirmed here, remains a puzzle. Even though our comparison with bright SOFIE clouds showed good qualitative agreement between temperature fluctuations and cloud occurrence (Nielsen et al., 2010), it may be that a limb viewing satellite 
has too coarse horizontal resolution to capture local temperature fluctuations for quantitative correlations. The recent result that the actual ice temperatures are lower than the air temperature (Petelina and Zasetsky, 2009; Hervig and Gordley, 2010) also suggests that the limb viewed temperature is really a mix of both cloudy (colder) and clear (warmer) airmasses. However, even ground based data (Hoffner et al., 2003) have recorded NLCs at temperatures as warm as $157 \mathrm{~K}$. Clearly this is a problem deserving of future study.

\section{Acknowledgements}

This work was supported by grants from the Office of Naval Research and the NASA AIM Science project. SHIMMER was a joint project between NRL, the DoD Space Test Program and the NASA Heliophysics Division. The NOGAPS-ALPHA analysis is also supported by a grant of computer time from the DoD Supercomputing Resource Centers. We thank Larry Coy for providing estimates of the vertical wind used in the CARMA calculations. Finally, we thank the entire AIM team led by J. M. Russell III for producing an excellent dataset.

\section{References}

Alexander, M.J., Rosenlof, K.H., 1996. Nonstationary gravity wave forcing of the stratospheric zonal mean wind. Journal of Geophysical Research 101, 23,465-23,474.

Allen, D.R., Coy, L., Eckermann, S.D., McCormack, J.P., Manney, G.L., Hogan, T.F., Kim, Y.-J., 2006. NOGAPS-ALPHA simulations of the 2002 Southern Hemisphere stratospheric major warming. Monthly Weather Review 134, 498-518.

Becker, E., Fritts, D.C., 2006. Enhanced gravity-wave activity and interhemispheric coupling during the MaCWAVE/MIDAS Northern summer program 2002. Annales Geophysicae 24, 1175-1188.

Becker, E., Mullemann, A., Lubken, F.-J., Kornich, H., Hoffmann, P., Rapp, M., 2004 High Rossby-wave activity in austral winter 2002: modulation of the general circulation of the MLT during the MaCWAVE/MIDAS northern summer program. Geophysical Research Letters 31, L24S03. doi:10.1029/2004GL019615.

Berger, U., von Zahn, U., 2007. Three-dimensional modeling of the trajectories of visible noctilucent cloud particles: an indication of particle nucleation well below the mesopause. Journal of Geophysical Research 112, D16204. doi:10.1029/2006JD008106.

Coy, L., Siskind, D.E., Eckermann, S.D., McCormack, J.P., Allen, D.R., Hogan, T.F., 2005. Modeling the August 2002 minor warming event. Geophysical Research Letters 32, L07808. doi:10.1029/2005GL022400.

Eckermann, S.D., Hoppel, K.W., Coy, L., McCormack, J.P., Siskind, D.E., Nielsen, K. Kochenash, A., Stevens, M.H., Englert, C.R., 2009. High-altitude data assimilation system experiments for the Northern Hemisphere summer mesosphere season of 2007. Journal of Atmospheric and Solar Terrestrial Physics 71, 531-551.

Englert, C.R., Stevens, M.H., Siskind, D.E., Harlander, J.M., Roesler, F.L., 2010. Spatial heterodyne imager for mesospheric radicals on STPSat-1. Journal of Geophysical Research 115, D20306. doi:10.1029/2010JD014398.

Espy, P.J., Fernandez, S.O., Forkman, P., Murtagh, D., Stegman, J., 2011. The role of the QBO in the inter-hemispheric coupling of summer mesospheric temperatures. Atmospheric Chemistry and Physics. 11, 495-502.

Fiedler, J., Baumgarten, G., Berger, U., Hoffmann, P., Kaifler, N., Lubken, F.-J., 2011 NLC and the background atmosphere above ALOMAR. Atmospheric Chemistry Physics Discussions 11, 5641-5679.

Garcia, R.R., 1987. On the mean meridional circulation of the middle atmosphere. Journal of the Atmospheric Sciences 44, 3599-3609.

Garcia, R.R., Stordal, F., Solomon, S., Kiehl, J.T., 1992. A new numerical model of the middle atmosphere, 1 , dynamics and transport of tropospheric source gases. Journal of Geophysical Research 97, 12967-12991.

Goldberg, R.A., et al., 2004. The MaCWAVE/MIDAS rocket and ground-based measurements of polar summer dynamics: overview and mean state structure. Geophysical Research Letters 31, L24S02. doi:10.1029/2004GL019411.

Gordley, L.L., et al., 2009. The solar occulation for ice experiment. Journal of Atmospheric and Solar-Terrestrial Physics 71, 300-315.
Hervig, M.E., Gordley, L.L., 2010. The temperature, shape, and phase of mesospheric ice from SOFIE observations. Journal of Geophysical Research 115 D15208. doi:10.1029/2010JD013918.

Hervig, M.E., Gordley, L.L., Russell, J.M., Bailey, S., 2009a. SOFIE PMC measurements during the Northern summer of 2007. Journal of Atmospheric and SolarTerrestrial Physics 71, 331-339. doi:10.1016/j.jastp.2008.08.010.

Hervig, M.E., Stevens, M.H., Gordley, L.L., Deaver, L.E., Russell, J.M., Bailey, S., 2009b. Relationships between PMCs, temperature and water vapor from SOFIE observations. Journal of Geophysical Research 114, D20203. doi:10.1029/ 2009JD012302.

Hitchman, M.H., Gille, J.C., Rodgers, C.D., Brasseur, G., 1989. The separated polar winter stratopause: a gravity wave driven climatological features. Journal of the Atmospheric Sciences 46, 410-422.

Hoffner, J., Fricke-Begemann, C., Lubken, F.-J., 2003. First observations of noctilucent clouds by lidar at Svalbard, $78^{\circ} \leftarrow$ N. Atmospheric Chemistry and Physics 3, 1101-1111.

Hoppel, K.W., Baker, N.L., Coy, L., Eckermann, S.D., McCormack, J.P., Nedoluha, G., Siskind, D.E., 2008. Assimilation of stratospheric and mesospheric temperatures from MLS and SABER in a global NWP model. Atmospheric Chemistry and Physics 8, 6103-6116.

Karlsson, B., Kornich, H., Gumbel, J., 2007. Evidence of interhemispheric stratosphere-mesosphere coupling derived from noctilucent cloud properties. Geophysical Research Letters 34, L16806. doi:10.1029/2007GL030282.

Karlsson, B., McLandress, C., Shepherd, T.G., 2009a. Inter-hemispheric mesospheric coupling in a comprehensive middle atmosphere model. Journal of Atmospheric and Solar Terrestrial Physics 71, 518-530. doi:10.1016/j/jastp. 2008.08.006.

Karlsson, B., Randall, C.E., Benze, S., Mills, M., Harvey, V.L., Bailey, S.M., Russell III, J.M., 2009b. Intraseasonal variability of polar mesospheric clouds due to inter-hemispheric coupling. Geophysical Research Letters, 36. doi:10.1029/2009GL040348.

Kornich, H., Becker, E., 2010. A simple model for the interhemispheric coupling of the middle atmospheric circulation. Advances in Space Research. 45, 661-668.

Nielsen, K., et al., 2010. Seasonal variation of the quasi 5 day planetary wave: causes and consequences for polar mesospheric cloud variability in 2007. Journal of Geophysical Research 115, D18111. doi:10.1029/2009JD012676.

Petelina, S.V., Zasetsky, A.Y., 2009. Temperature of mesospheric ice retrieved from the O-H stretch band. Geophysical Research Letters 36, L15804. doi:10.1029/ 2009GL038488.

Remsberg, E.E., et al., 2008. Assessment of the quality of the Version 1.07 temperature-versus-pressure profiles of the middle atmosphere from TIMED/SABER. Journal of Geophysical Research 113, D17101.

Russell III, J.M., et al., 2009. The Aeronomy of Ice in the Mesosphere (AIM) mission: overview and early science results. Journal of Atmospheric and Solar Terrestrial Physics 71, 289-299. doi:10.1016/j.jastp.2008.08.011.

Schwartz, M.J., et al., 2008. Validation of the AURA microwave limb sound temperature and geopotential height measurement. Journal of Geophysical Research 113, D15S11.

Shettle, E., Nedoluha, G.E., DeLand, M.T., Thomas, G.E., Olivero, J.J., 2010. SBUV obsevations of polar mesospheric clouds compared with MLS temperatures and water vapor measurements. Geophysical Research Letters 37, L18810. doi:10.1029/2010GL044132.

Siskind, D.E., Eckermann, S.D., McCormack, J.P., Alexander, M.J., Bacmeister, J.T., 2003. Hemispheric differences in the temperature of the summertime stratosphere and mesosphere. Journal of Geophysical Research 108, 4051. doi:1029/ 2002JD002095.

Siskind, D.E., Stevens, M.H., Englert, C.R., 2005a. A model study of global variability in mesospheric cloudiness. Journal of Atmospheric and Solar Terrestrial Physics 67, 501-513.

Siskind, D.E., Coy, L., Espy, P., 2005b. Observations of stratospheric warmings and mesospheric coolings by the TIMED SABER instrument. Geophysical Research Letters 32, L09804. doi:10.1029/2005GL022399.

Siskind, D.E., Hervig, M., Gumbel, J., Stevens, M.H., 2007. Polar mesosphere cloud mass and the ice budget: 3, application of a coupled ice-chemistry-dynamics model and comparison with observations. Journal of Geophyiscal Research 113, D08303. doi:10.1029/2006JD007499.

Stevens, M.H., Conway, R.R., Englert, C.R., Summers, M.E., Grossmann, K.U., Gusev, O.A., 2001. PMCs and the water frost point in the Arctic summer mesosphere. Geophysical Research Letters 28, 4449-4452.

Stevens, M.H., Englert, C.R., Hervig, M., Petelina, S.V., Singer, W., Nielsen, K., 2009. The diurnal variation of polar mesospheric cloud frequency near $55^{\circ} \mathrm{N}$ observed by SHIMMER. Journal of Atmospheric and Solar-Terrestrial Physics 71, 401-407.

Stevens, M.H., et al., 2010. Tidally induced variations of polar mesospheric cloud altitudes and ice water content using a data assimilation system. Journal of Geophysical Research 115, D18209. doi:10.1029/2009JD013225.

Yulaeva, E., Holton, J.R., Wallace, J.M., 1994. On the cause of the annual cycle in tropical lower-stratospheric temperatures. Journal of the Atmospheric Sciences 51, 169-174. 